\title{
Analyzing Misconception of Exponent for High School in Makassar
}

\author{
St. Nur Humairah Halim1 Randy Saputra Mahmud ${ }^{1, *}$, Sitti Rahmah Tahir ${ }^{1}$, \\ Abdul Gaffar ${ }^{1}$, Sri Wulandari ${ }^{1}$, Andi Trisnowali ${ }^{2}$ \\ ${ }^{1}$ Universitas Muhammadiyah Makassar \\ ${ }^{2}$ Universitas Muhammadiyah Bone \\ *Corresponding author. Email: randy@unismuh.ac.id
}

\begin{abstract}
This study aims to analyze the misconceptions experienced by students in exponential material. This research was conducted in Class X IPA 1 SMAN 4 Makassar in the odd semester 2019/2020 academic year. The subjects in this study were three students who were selected based on the type of misconception. This type of research is descriptive qualitative research. The instruments used were diagnostic tests and interview guides. This study analyzed the types of students' misconceptions, namely, classification misconceptions, correlational misconceptions, and theoretical misconceptions. The results of this study indicate that of the three subjects who experience a classification misconception caused by a lack of understanding of mathematical symbols, they rarely ask the teacher. Correlational misconceptions caused by the lack of variety in the questions being worked on, lazy to repeat learning at home. Meanwhile, theoretical misconceptions are caused by a lack of practice in doing questions, embarrassed to ask the teacher.
\end{abstract}

Keywords: Misconception, Exponent, Mathematics Learning.

\section{INTRODUCTION}

Effective learning is learning that can educate students to achieve maximum progress according to their abilities. In reality, not all students can achieve maximum progress in the learning process. Students often face problems and need help from the surrounding environment to resolve the issue.

One of the problems of education is related to planting understanding concepts. Wher e students sometimes misunderstood concepts. The mistake of understanding the concept by the student will consistently affect the effectiveness of the next learning process of the student concerned. According to [1] the low mastery of concept affects the low value of Minimum Criteria Exhaustiveness (KKM) on concept and fields of study.

Mathematics is a subject full of concepts. Concepts composed in mathematics is required for other scientific materials [2]. Understanding this concept will also be a provision for the student to learn the next material [3]. On the issue of understanding concepts, there are still many students who, after studying mathematics, are unable to understand the concepts. Whereas mathematics learning emphasizes concepts, so it becomes a problem when students misconception in math learning. The difference between theoretical concepts and the imprecise notions of the scholarship leads to misconceptions [4]. If students misunderstood the concepts of mathematics, it affects their understanding of the next materials. Therefore, the teacher needs to analyze student misconceptions because not all students dare to express what the student thinks and feels. The problem that occurs a lot is the silence of students during learning because the student not understands. But instead, the student experiences confusion that causes the student to misinterpret a concept.

Based on interviews conducted with teachers of mathematics subjects in SMAN 4 Makassar, there are still students who experience misconceptions, especially exponent material. Then a solution is needed that can break the concept error that has been built by students. To help students precisely need to know in advance what difficulties or problems the student faces, then 
analyze and formulate solutions. In analyzing errors in understanding student misconception used is a diagnostic test.

Diagnostic tests are tests that can use to know weaknesses and strengths in a particular lesson. The most suitable misconception diagnostic test applied to a large number of students is a four-tier multiple-choice diagnostic test [5]. The type of diagnostic test used for analyses on a misconception is a multiple-choice diagnostic test with open reasons. The diagnostic test can be developed to identify the conceptual understanding is the diagnostic test by two-tier multiplechoices [6]. But multiple-choice diagnostic tests with open reasons have flaws, namely the difficulty of distinguishing the answers of students who do not understand concepts and students who experience misconceptions. One way that is used by experts to identify misconceptions is by using multiple-choice diagnostic instruments [7] this tool can measure the level of student understanding of the concept. Therefore multiple-choice diagnostic tests with open reasons will be combined with CRI (Certain of Response Index). The method is universally applicable in science, mathematics, engineering and other fields, from middle to graduate school [8]. CRI itself is a method used to measure students' confidence in answering questions. CRI developed in the form of a confidence level scale.

There are some previous researcher associated with this study, such as [9], [10], [11], and [12] who had conducted similar research and proved that diagnostic test could be used to identify students' conceptual understanding. Based on this description, it can be noted that the identification of misconceptions in exponent material using diagnostic tests is very important. With diagnostic tests, teachers can assists students to address misconceptions that occur.

\section{METHOD}

This type of research is qualitatively descriptive that focused on misconceptions experienced by students in exponent material with the type of misconceptions. Research instruments used are tested and interviews. The study was conducted in October 2019. A total of 24 students in the high school 4 Makassar in grade X1 science was given multiple-choice diagnostic tests with open reason, then selected three subjects that represent each one of the most dominant types of misconceptions. Subject selection based on multiple-choice diagnostic test interpretation results with CRI. After that, three selected subjects conducted interviews. Data collected from observation, test, interview, and documentation. Observations are made directly during mathematics learning, The tests were given to sort out the students into four categories (understanding the material, material inconsistencies, lucky guesses, and conceptual errors) and to determine the type of misconceptions that students experience.

\section{RESULT AND DISCUSSION}

\subsection{Result}

Each type of misconception represents one subject. The reference is the subject of the highest misconception, so the student who is the selected research subject is presented in table 1. Selected subjects illustrated in table 1 are grouped into three categories. Subject S2 is the highest type of classificational misconceptions, subject S5 is the highest type of correlational misconceptions, and subject S15 is the highest type of theoretical misconceptions.

Table 1. Selected research subjects

\begin{tabular}{|c|c|c|}
\hline No & Types of Misconceptions & Subject Code \\
\hline 1 & Classificational Misconception (MKL) & S2 \\
\hline 2 & Correlational Misconceptions (MKR) & S5 \\
\hline 3 & Theoretical Misconceptions (MTR) & S15 \\
\hline
\end{tabular}

\subsubsection{Description of Classificational Misconception Data}

The following is the answer to subject S2 which is in type classification misconception shows that figure 1 .

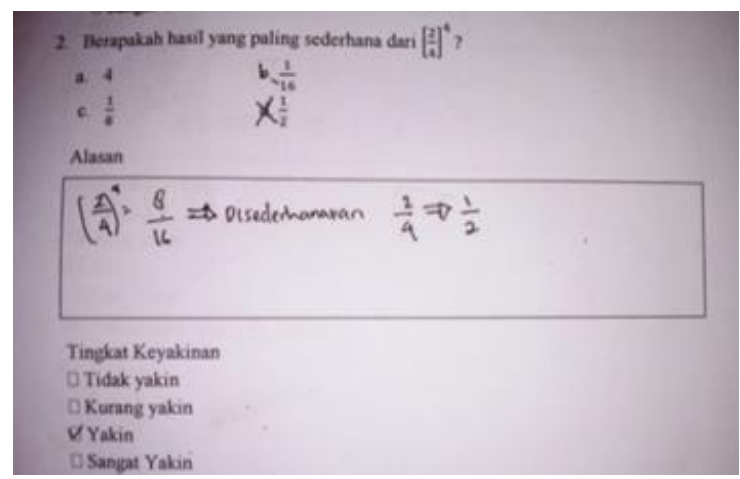

Figure 1 Answer sheet S2.

It can know from figure 1, the subject of S2 chooses the wrong answer as in the picture, where the answer displayed is also wrong. The level of confidence chosen is certain. Based on the table, the score of diagnostic test $\mathrm{S} 2$ has a score of $0-3$. The answer gets a score of 0 because the answer is worth wrong. The confidence level gets a score of 3 because S2 chooses a sure choice. It seems very clear from the reasons that the subject is not by following per under the concept of the exponent. So S2's answer includes a group of misconceptions. Based on indicators of the types of misconception, in exponent material, $\mathrm{S} 2$ is categorized as classificational misconceptions. 


\subsubsection{Description of Correlational Misconception Data}

The following is the answer to subject $\mathrm{S} 5$ which is in type classification misconception shows that figure 2 .

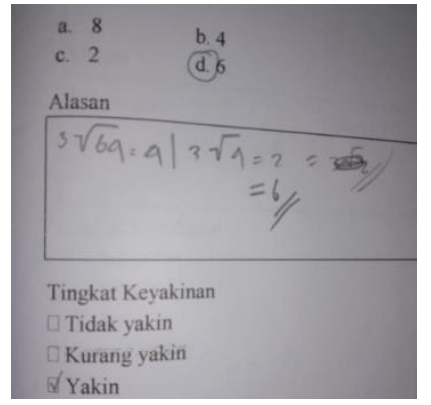

Figure 2 Answer sheet S5.

It can find from figure 2 that the S5 subject selects an answer that is of incorrect value, for reasons such as in the image, where the subject reason presented incorrectly. The level of subject confidence chosen is certain. Based on the interpretation table, the S5 diagnostic table has a score of 0-3. For answer gets a score of 0 because the answer is worth wrong. The confidence level gets a score of 3 because S5 chooses a sure choice. It seems very clear from the reason that the S5 does not conform to the concept of exponents. Therefore the answer to S5 belongs to the group of misconceptions. Based on indicators of the type of misconception in exponent material, S5 is categorized as correlational misconceptions.

\subsubsection{Description of Theoretical Misconception}

The following is the answer to subject S15 which is in type classification misconception shows that figure 3 .

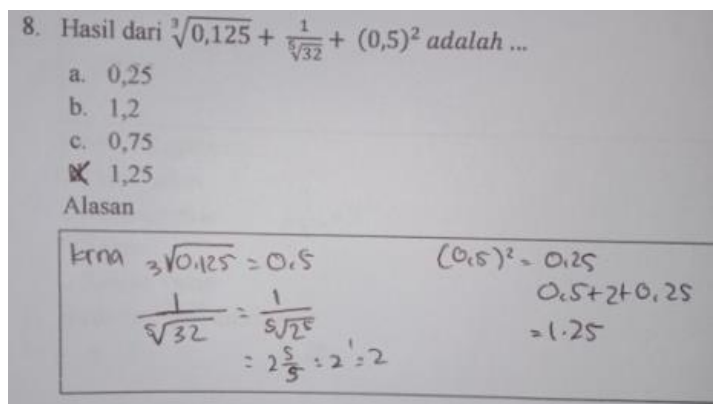

Figure 3 Answer sheet S15.

It can find from figure 3 the subject S15 selects the answer d, with reasons such as in the image, where the subjects' reason presented by S15 is incorrect. And the level of confidence chosen is certain. Based on the interpretation table, the subject diagnostic figure 3 has a score of $0-3$. The answers get a score of 0 because the reason for that answer is worth wrong. The confidence level scored 3 because the S15 subject chose a sure choice. It seems very clear from the reasons that the subject S15 presented does not conform to the concept of exponents. Based on the answer, subject S15 is in the theoretical misconceptions.

\subsection{Discussion}

Based on the test results and interviews, it can conclude that $\mathrm{S} 2$ subjects experience misconceptions in understanding the concept of determining the properties and rules of the exponent. This misconception occurs because the subject of S2 assumes that solving a problem with a fractional exponent is to multiply between the base number and its power. The type of misconception experienced by $\mathrm{S} 2$ is a classificational misconception. It because S2 subjects meet one of the indicators of the classificational misconceptions, determine that wrong in apply properties and rules of exponents material. Based on the results of the interview, the cause of the misconception in the subject S2 is because the subject directly multiplies the base number by its power. In the subject learning, S2 says many encounter symbols, and not all of them are understood. S2 subjects do not dare to ask the teacher about the material.

Based on the tests and interviews, it can conclude that subject S5 categorize in correlational misconceptions. It's because to solve the question, subject S5 assumes in the first step isn't finished. The subject S5 continues to finish, the result of the subject S5 obtained in the first completion still changed to another. Subject S5 also wrong in multiplying the roots. The misconception experienced by S5 is correlational. It is because S5 meets several indicators of correlational misconceptions, incorrect in resolving power numbers using exponent properties and wrong in simplifying the number of roots to the power of numbers. Based on the interview result, the cause of the misconception of the subject S5 was the lack to repeat lessons at home. The subject of S5 also explained that he understands when the teacher presents an example of the problem, but when the form of the question has been started, subject $\mathrm{S} 5$ is confused to resolve it.

Based on the results of tests and interviews, it can conclude that the subject S15 experienced a misunderstanding in summing up and reducing the strength of the numbers. During the interview, S15's explanation showed that the subject did not understand the exponent's exponent nature. This type of misunderstanding experienced by the subject S15 is a theoretical misunderstanding. It's because the subject S15 was included in one of the indicators of theoretical misunderstanding, namely errors in operating in the form of summation and reduction of the strength of numbers.

The cause of misconception with S15 subjects, it's because it was rare to practice working on examples of 
problems when outside the hours of math lessons. This situation makes it easy for the subject to forget the material. When the subject forgot the material, S15 is embarrassed to ask the teacher to understand the intent of each existing formula.

\section{CONCLUSION}

Based on the analysis of data from 3 selected subjects, it can conclude that the type of misconception experienced is a classificational misconception. The use of traits and rules in the exponent. Correlational misconceptions in simplifying power numbers using the properties. Theoretical misconceptions in the summation and reduction of power numbers. The causes of such misconceptions include internal and external influences. Internal influence due to lack of training in student, lack of reading and understanding of the intent of each formula, lack of learning motivation, and students learn depending on whether or not the teacher's job is available. The external influence is the lack of intense communication with students.

\section{REFERENCES}

[1] W. Winarso, T. Toheri, A case study of misconceptions students in the learning of mathematics; the concept limit function in high school, vol. 4, JRPM, Cirebon, 2017, pp 120-127. DOI: https://doi.org/10.21831/jrpm.v4i1.12060

[2] R.S. Mahmud, A. Syamsuadi, Nursakiah, Pembelajaran kooperatif STAD dengan strategi penugasan multi level instruction pada materi matematika, vol. 2, JHM, 2019, pp 37-52, DOI: https://doi.org/10.30862/jhm.v2i1.54

[3] R. Hayati, W. Setyaningrum, Identification of misconceptions in middle school mathematics utilizing certainty of response index, J. Phys.: Conf. Series 1320 012041, 2019. DOI: https://doi.org/10.1088/1742-6596/1320/1/012041

[4] Rochmad, M. Kharis, A. Agoestanto, M.Z. Zahid, Mashuri, Misconception as a critical and creative thinking inhibitor for mathematics education students, vol 7, UJME, Semarang, 2018, pp 57-62, DOI: https://doi.org/10.15294/ujme.v7i1.18078

[5] F.U. Ermawati, S. Anggrayni, L. Isfara Misconception profile of students in senior high school IV sidoarjo east java in work and energy concepts and the causes evaluated using four-tier diagnostic test, J. Phys.: Conf. Series 1387012062 , 2019. DOI: https://doi.org/10.1088/17426596/1387/1/012062

[6] S. Mania, et al, Diagnostic test instrument of twitier multiple choices to identify mathematic concept understanding, J. Phys.: Conf. Series 1114
012045, 2018. DOI: https://doi.org/10.1088/17426596/1114/1/012045

[7] I. Yunanda, H. Susilo, A. Ghofur, Misconceptions identification on biodiversity and protist using multipe-choice open reason, vol 12, Biosfer, Malang, 2019, pp 170-181, DOI: https://doi.org/10.21009/biosferjpb.v12n2.170-181

[8] S. Hasan, D. Bagayoko, E.L. Kelley, Misconceptions and the certainty of response index (CRI), Phys. Educ. 34(5), 1999. DOI: https://doi.org/10.1088/0031-9120/34/5/304

[9] G.R. Utami, H. Firman, N. Nahadi, Development of computer based two-tier multiple choice diagnostic test to identify misconceptionson chemical bonding, J. Physics.: Conf. Series 1157 042033, 2019. DOI: https://doi.org/10.1088/1742$6596 / 1157 / 4 / 042033$

[10] E. Susilowati, Suyidno, T. Mayasari, N. Winarno, Using three-tier diagnostic test to asses students' misconception of simple harmonic oscillation, J. Phys.: Conf. Ser. 1422 012023, 2020. DOI: https://doi.org/10.1088/1742-6596/1422/1/012023

[11]S. Anggrayni, F.U. Ermawati, The validity of fourtier's misconception diagnostic test for work and energy concepts, J. Phys.: Conf. Ser. 1171012037 , 2019. DOI: https://doi.org/10.1088/1742$6596 / 1171 / 1 / 012037$ 